\title{
РЕКОРДЫ НА УРОВНЕ СВЕТА: КАК ИЗОБРЕТЕНИЯ РОССИЙСКИХ УЧЕНЫХ ЛЕГЛИ В ОСНОВУ МЕЖДУНАРОДНОГО ПРОРЫВА
}

\section{RECORDS AT THE LIGHT LEVEL: HOW THE INVENTIONS OF RUSSIAN SCIENTISTS LIED THE BASIS OF THE INTERNATIONAL BREAKTHROUGH}

И.А.Родионов, к.т.н., директор НОЦ Функционапьные Микро/Наносистемы МГТУ им. Н.Э.Баумана, (ORCID: 0000-0002-8931-5142) / oefremova@bmstu.ru

I.A.Rodionov, Cand. of Sc. (Technical), director of FMN Laboratory based on Bauman Moscow State Technical University

DOI: $10.22184 / 1993-8578.2020 .13 .7-8.408 .412$

Получено: 09.12.2020 г.

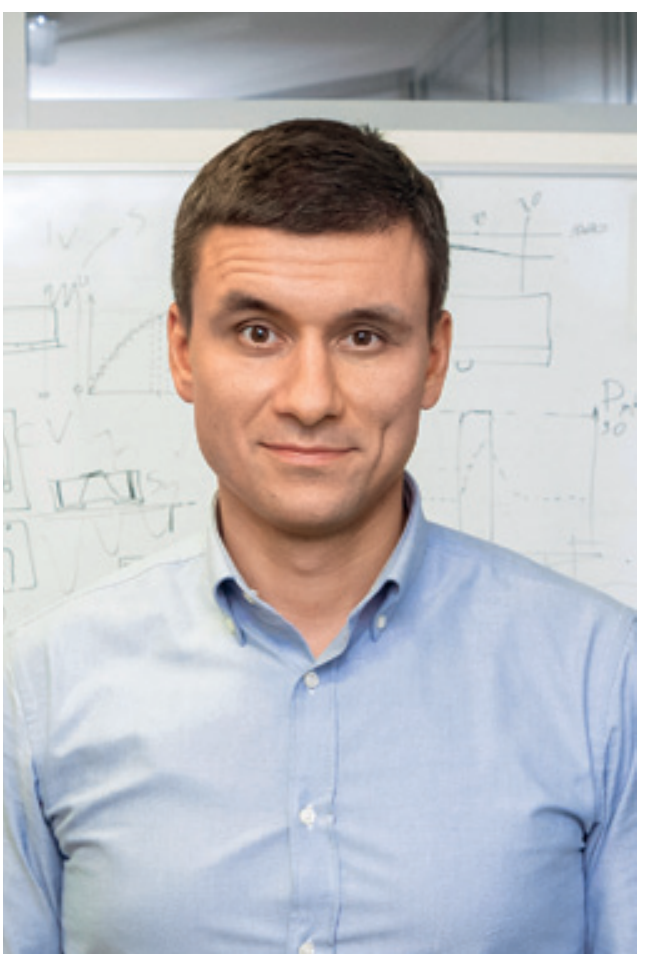

Технологии будущего создаются в настоящем. Где они рождаются? Кто их создает? Какой путь приходится пройти для создания современных высокотехнологичных центров научной и инженерной мысли? О многих новейших разработках и направлениях, таких как плазмоника и нанофотоника, SCULL-технология, о "русском методе" обучения архитекторов будущего рассказывает Илья Анатольевич Родионов, кандидат технических наук, директор НОЦ Функциональные Микро/Наносистемы МГТУ им. Н.Э.Баумана и ФГУП ВНИИА им. Н.Л. Духова. Future technologies are created in the present. Where are they born? Who creates them? What path does it take to create modern high-tech centers of scientific and engineering thought? llya Anatolyevich Rodionov, candidate of technical sciences, director of FMN Laboratory based at Bauman Moscow State Technical University, tells about many of the latest developments and scientific areas, such as plasmonics and nanophotonics, SCULL technology, and the "Russian method" of teaching architects of the future.
Илья Анатольевич, за пять лет работы НОЦ ФМН стал одним из ключевых российских исследовательских центров, разрабатывающих технологии в области нанофотоники, квантовых технологий и бионанотехнологий. С чего все начиналось?

НОЦ Функциональные Микро/Наносистемы был создан в 2014 году и открыт после завершения строительства в бауманском улк в 2015 году. В основе идеи создания нашего центра лежит разработка технологий и устройств на новых физических принципах. Совместно с нашими международными партнерами мы создаем технологии следующего поколения, которых сегодня в мире еще не существует, но они станут повседневными через 10-15 лет и будут приносить пользу людям. 


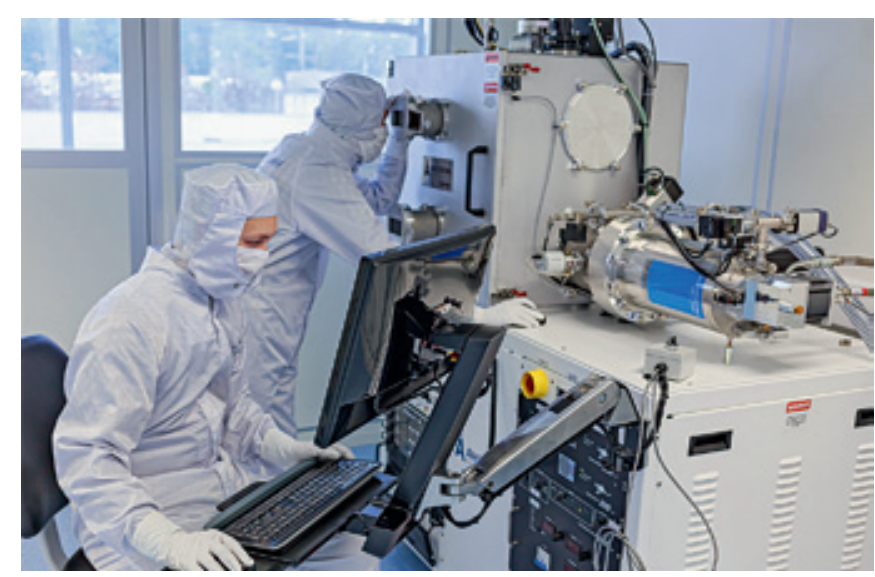

Рис.1. Инженеры НОЦ ФМН проводят процесс формирования эпитаксиальных серебряных пленок

Fig.I. FMN Laboratory engineers control the process of epitaxial silver films growth

К созданию центра мы привлекли более десятка ведущих мировых компаний, и это позволило обеспечить уникальную инфраструктуру для функционирования сложнейшего оборудования . В нашей "чистой комнате" в режиме реального времени поддерживаются в оптимальном соотношении более 300 параметров инфраструктурных подсистем, что критически важно, когда речь идет о работе с такими технологиями и суб-10 нм наноструктурами. В центре создана технологическая линия с учетом лучших мировых практик - это, отчасти, результат плотного взаимодействия с ведущими нанотехнологическими центрами Европы, США и Азии. Сегодня у нас более 20 международных партнеров.

С точки зрения исследований и разработок ведущих мировых технологий нашим мощным дебютом стал проект по наноплазмонике. Реализованный командой колоссальный объем работы открыл дорогу к тем прорывным решениям, которые мы сегодня используем в разработках в области нанофотоники и оптики, бионанотехнологий, микроэлектромеханических (МЭМС) систем и, конечно, квантовых технологиях.

Одним из основных открытий НОЦ ФМН, ставшим новым словом в области создания тонкопленочных материалов, стала технология эпитаксиального роста SCULL. Почему она настолько важна?

Плазмоника, как и нанофотоника в целом - стремительно развивающееся направление исследований мирового научного сообщества. Для целого ряда перспективных приборов нанофотоники

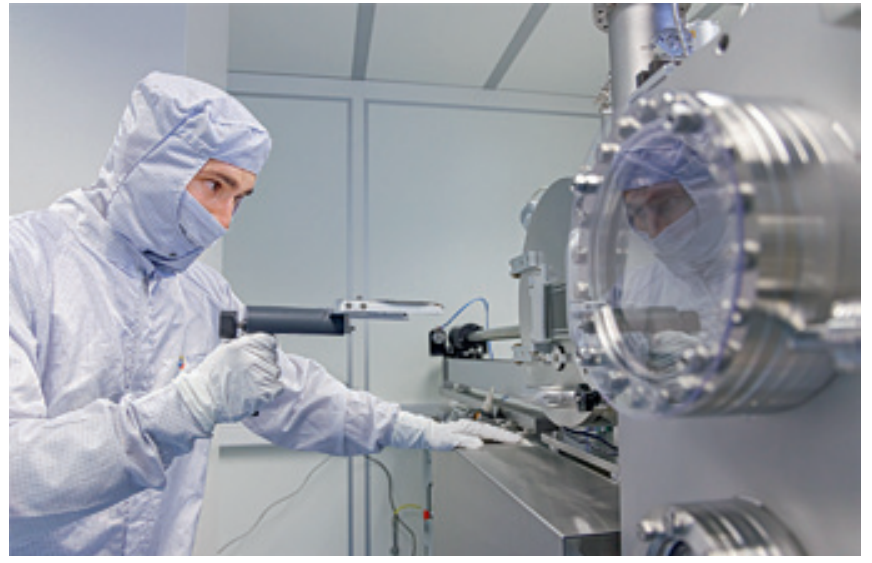

Рис. 2. Инженер НОЦ ФМН во время работы с установкой осаждения тонких пленок

Fig.2. FMN Laboratory engineers watch the thin films deposition

(низкопороговые нанолазеры, одномолекулярные биосенсоры, эффективные солнечные батареи, оптические и квантовые суперкомпьютеры нового поколения) требовались "совершенные" металлы практически без потерь - только тогда все начинало работать. До определенного момента плазмонных металлов с предсказанными десятки лет назад свойствами (здесь чаще всего имеется в виду серебро и золото), свободных от потерь, не было ни в одной лаборатории мира, что существенно ограничивало широкое практическое внедрение плазмонных устройств.

На протяжении 60 лет ученые всего мира теоретически предполагали, что совершенные тонкие пленки серебра обладают минимальными потерями среди всех металлов, но не могли подтвердить это экспериментально из-за фундаментальных технологических ограничений, связанных с особыми природными свойствами серебра. А конкурентов у серебра, с точки зрения омических потерь, которые так важны для устройств плазмоники, до сих пор не существует. Мы в НОЦ ФМН разработали комплекс технологий, открывающий принципиально новые горизонты в изучении фундаментальной физики и практической реализации важнейших квантовых устройств.

Таким образом, теория была доказана на практике в МГТУ им. Н.Э.Баумана?

Именно! Но это была довольно долгая история. Мы задумали свою разработку с партнерами из ИТПЭ РАН еще в 2014 году. Подробно изучив несколько сотен статей, спроектировали 


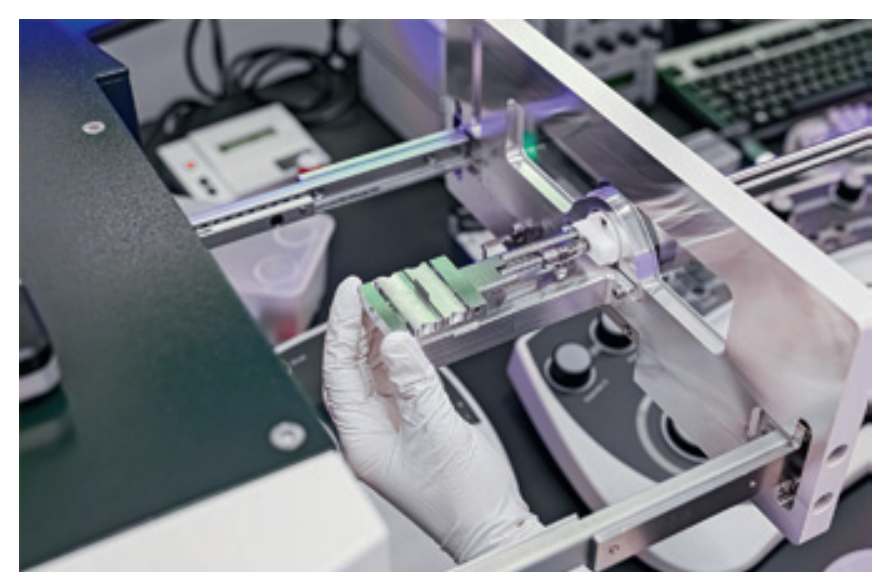

Рис. 3. Подготовка образца тонкой серебряной пленки к измерениям в сканирующем электронном микроскопе

Fig.3. Preparing a thin silver film sample to measure in a scanning electron microscope

оригинальную вакуумную установку и, как сейчас помню, практически с чертежами в руках пришли к ректору МГту им. Н.Э.Баумана за помощью с финансированием. К счастью, Анатолий Александрович сразу оценил перспективы этих технологий и выделил необходимые средства. В итоге изготовление вакуумной установки одной из лучших компаний из Канады и тонкая доработка оборудования у нас в центре заняли около полутора лет. После этого начались тяжелые будни: примерно за год непрерывной работы мы изготовили и проанализировали более тысячи образцов, пока окончательно не нашли тот самый нестандартный механизм формирования тонких пленок металлов - SCULL, открывший нам дорогу к международному партнерству.

В чем особенности разработанного вами подхода? Каковы характеристики пленок металлов нового типа?

SCULL-технология предполагает "сборку" ультрагладких тонких пленок серебра и других металлов за счет управления их ростом на атомарном уровне. Соответственно, с ее применением мы умеем создавать практически структурно идеальные тонкие пленки с шероховатостью поверхности на уровне диаметра атома самого материала пленки, то есть 90-200 пм - в миллион раз меньше диаметра волоса. При этом подчеркну, что преимуществом нашего метода является не только беспрецедентное качество осаждаемых металлов, но и то, что он является абсолютно повторяемым для широкого спектра материалов и существенно более дешевым по сравнению со стандартной эпитаксией. Он может применяться практически в любой современной лаборатории, решая задачи инженеров в областях нанофотоники, квантовых вычислений и коммуникаций, биомедицины и энергетики.

SCULL-технология прошла стадию патентования? Конечно, российский патент был оформлен сразу же после разработки технологии, сейчас же мы находимся на завершающей стадии получения патента США, который установит приоритет России в 140 странах.

Каких рекордов вам удалось достичь благодаря применению пленок с уникальными характеристиками?

Во-первых, мы, вместе с коллегами из ИСАН РАН, вновь переписали учебники по физике. Дело в том, что атомарно гладкая
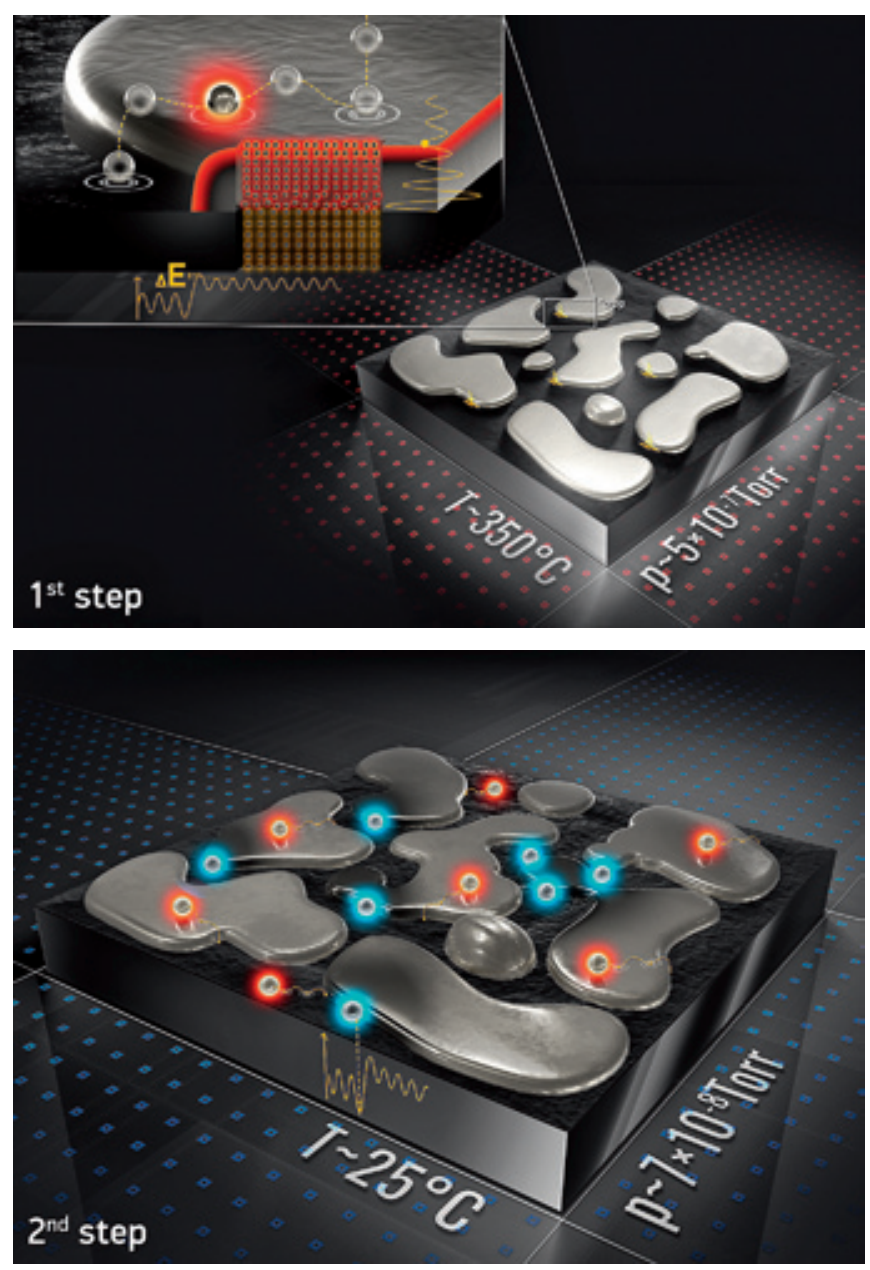

Puс.4. Этапы формирования эпитаксиальных SCULL-пленок Fig.4. Stages of epitaxial SCULL films forming 


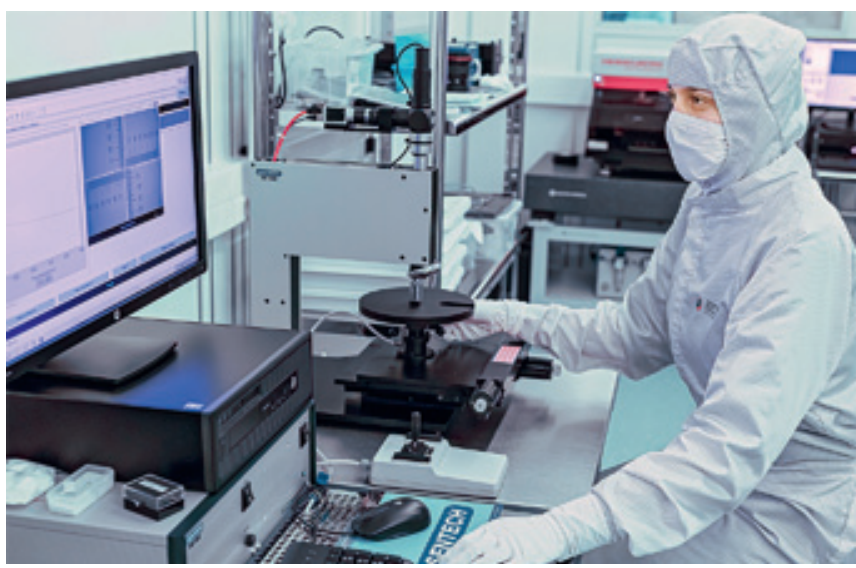

Рис.5. Инженер НОЦ ФМН проводит измерения толщины эпитаксиальных пленок

Fig.5. An engineer of FMN laboratory conducts measurements of the epitaxial films thickness

монокристаллическая тонкая SCULL-пленка серебра становится уникальным элементом оптической среды с чрезвычайно низкими потерями. Мы экспериментально установили, что поверхностная плазмон-поляритонная волна, возбуждаемая на поверхности наших пленок, имеет длину распространения порядка 200 мкм. Это вдвое превышает опубликованные ранее в мире результаты и соответствует теоретическому максимальному значению для пленок серебра.

Во-вторых, на базе SCULL создано сразу несколько биосенсоров с рекордной чувствительностью к разным биологическим маркерам и модельным молекулам. Один из разработанных сенсоров может детектировать три части вещества на триллион частей раствора, и это пока непревзойденный показатель. Совместно с командой из CUNY (The City University of New York) и Queen's College на базе SCULL-пленок разработан плазмонный нанолазер с рекордными спектральными характеристиками, детектирующий до семи частиц вещества в 100 млн частиц раствора.

И наконец, в партнерстве с группой Владимира Шалаева из Университета Пердью, Семеном Богдановым из Иллинойского университета в Урбана-Шампейн, исследовательской группой MIT нам удалось создать однофотонный источник с рекордной скоростью излучения: 35 млн одиночных фотонов в секунду.

Расскажите, пожалуйста, о вашем взаимодействии с коллегами из США. В чем оно состоит?

С Владимиром Шалаевым мы встретились на одной из научных конференций в 2017 году.

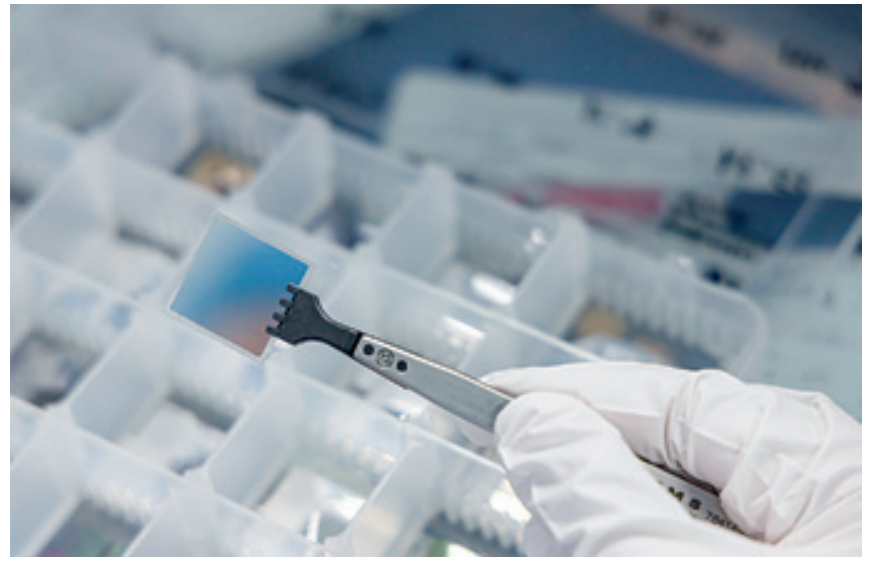

Рис.6. Эпитаксиальная пленка серебра, осажденная по SCULL-mexнологии

Fig.6. SCULL-deposited epitaxial silver film

Коллеги работали над созданием плазмонного источника одиночных фотонов, который стал бы надежной частью "квантовой триады" источник - волновод - детектор, но сталкивались с той же вечной проблемой - потерями. Все элементы квантовой цепочки должны быть изготовлены из почти идеальных материалов и настолько совершенно, чтобы не потерялся ни один фотон. Мы предоставили американским коллегам несколько образцов для измерений, и результаты их приятно удивили. Ключом к успеху стало усиление излучения фотонов плазмонными наноструктурами, выполненными на основе монокристаллического SCULL-серебра с рекордно низкими оптическими потерями.

\section{Получается, что SCULL-серебро усиливает излу- чение в источнике?}

Фотонный источник, который удалось разработать нашим коллегам из США, состоит из наноалмаза с NV-центром (азотозамещенная вакансия - один из точечных дефектов алмаза. Прим. ред.) и плазмонной наноструктуры в виде серебряного куба размером около 100 нм, который лежит на серебряной кристаллической подложке. Каждая такая структура содержит два ключевых оптических элемента: резонатор и антенну. Резонатор необходим для увеличения скорости фотонной эмиссии NV-центра, а антенна - для эффективного излучения эмиссии в окружающую среду. Рекордное увеличение скорости генерации фотонов в источнике достигается благодаря значительному усилению взаимодействия света c NV-центром, а оно, в свою 


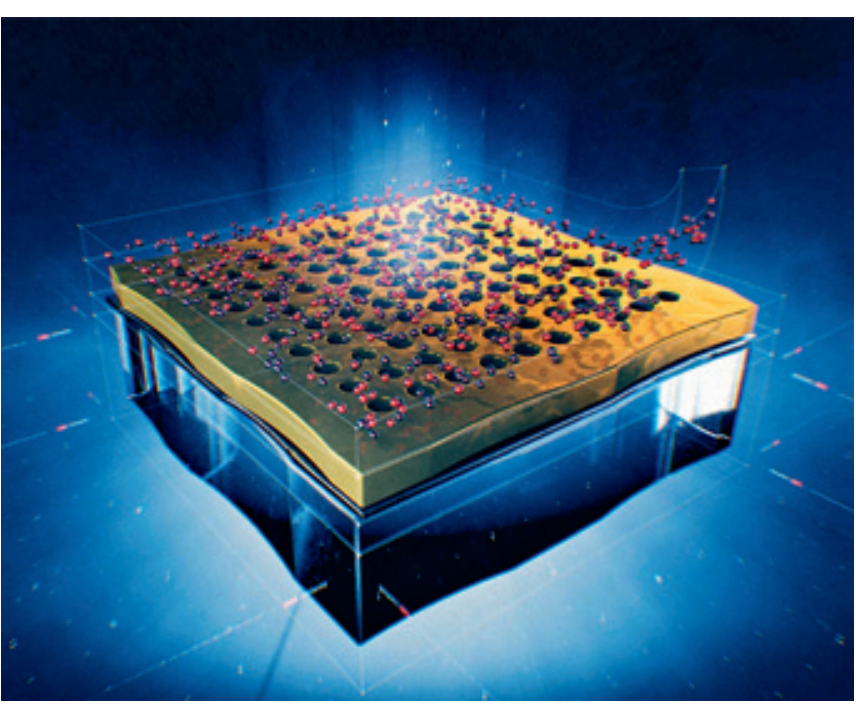

Pис.7. Биосенсор с рекордной чувствительностью

Fig.7. Biosensor with the record sensitivity

очередь, обеспечивается практически идеальным качеством наноструктур из SCULL-серебра.

Кстати, комплексное математическое моделирование источника было проведено под руководством доктора Якова Хургина из John Hopkins University - одного из ведущих мировых экспертов в области нанофотоники. Группа доктора Хургина определила фундаментальные пределы усиления квантового излучения в системах подобной нашей. Результаты нашей работы были опубликованы в ведущих журналах Nano Letters и Optica.

Как долго SCULL-пленки могут выполнять свою функцию в разрабатываемых приборах и устройствах? Серебро - материал недолговечный, стареющий со временем.

Мы на работе шутим, что SCULL-пленки исполнили мечту человечества: победили старость! На протяжении двух лет мы в команде с ИТПэ РАН исследовали монокристаллические пленки серебра толщиной от 25 до 70 нм на кремниевых подложках. Для чистоты эксперимента применяли разные методы: от спектроскопической эллипсометрии до сканирующего СэМа и стилусной профилометрии. Смотрели морфологию поверхности, кристаллическую структуру и, конечно, оптические характеристики металлов.

Мы установили, что следы деградации серебра проявлялись спустя 7-19 месяцев после осаждения и, что очень важно, были связаны с качеством самого материала, а не с химическими соединениями: "примесей" $\mathrm{AgCl}, \mathrm{Ag}_{2} \mathrm{~S}, \mathrm{Ag}_{2} \mathrm{O}$,
$\mathrm{Ag}_{2} \mathrm{CO}_{3}$ мы не нашли! Блестящий результат продемонстрировало SCULL-серебро толщиной 35-50 нм. Идеальная структура металла и низкая шероховатость поверхности обеспечили ему не только уникальные свойства, но и стабильность с течением времени. Это снимает фундаментальные ограничения по времени работы с серебром и позволяет создавать стабильные фотонные устройства на его основе.

Расскажите чуть подробнее о вашей команде. Как вы подбираете ребят? У вас работают только выпускники МГТУ? Как в НОЦ ФМН реализуется "русский метод обучения", которым славится "бауманка"?

В наш центр попадают лучшие из лучших студентов и аспирантов - причем не только из "бауманки", но и других ведущих вузов, включая МГУ и Физтех. Мы - научная банда из молодых ученых и инженеров: средний возраст сотрудников сегодня не превышает 30 лет! Это особенные люди, заинтересованные и преданные своему делу.

Бауманский "русский метод" предполагает обучение на реальных, "боевых" задачах. Я всегда говорю, что в нашем НОЦ нет студентов, есть полноправные участники проектов. Для того чтобы получить доступ к оборудованию, ребятам необходимо сдать экзамен на знание правил поведения и работы внутри чистокомнатных помещений. Следующий шаг - многоступенчатая (и зачастую многомесячная) система обучения работы на оборудовании, включая многочисленные стажировки у наших международных партнеров и получение доступа. Требования высокие не спроста: стоимость отдельных установок в чистом помещении достигает 2-3 млн евро.

\section{Что бы вы хотели сказать читателям нашего} журнала?

Мне хотелось бы пожелать коллегам удачи в реализации поставленных целей и самых смелых проектов. Желаю найти и успешно взаимодействовать с сильными научными и индустриальными партнерами, включая передовые международные команды. На нашем опыте можно убедиться, насколько эффективным может быть такое сотрудничество. Очень важно, чтобы отрасль нанотехнологий в России вышла на новую орбиту развития и обеспечивала нашей стране прогресс по прорывным технологическим направлениям.

Спасибо за интересную беседу! 
